Hordyk, S-R, Ben Soltane, S and Hanley, J. (2013). Sometimes you have to go under water to come up: A poetic, critical realist approach to documenting the voices of homeless immigrant women. Qualitative Social Work 13(2): 203220 .

\title{
Sometimes you have to go under water to come up: A poetic, critical realist approach to documenting the voices of homeless immigrant women
}

\begin{abstract}
Methodological debates concerning feminist research design tend to focus more on the process of data collection than on the process of data representation. Nevertheless, data representation is fraught with difficulties, especially in communicating research findings concerning vulnerable populations to diverse individuals and groups. How do feminist social work researchers represent the voice of the research participants to community and service organizations while simultaneously meeting the expectations of the academic or political institutions soliciting the research? In this paper, we discuss how we approached this dilemma with data collected through a research study on immigrant women experiencing homelessness and housing insecurity. Guided by feminist methodological principles, we drew on the tenets of critical realist theory, integrating this analysis with poetic inquiry to reconstruct the women's voices in the representations of research data. In this article, we discuss these modalities and provide two case examples to illustrate their application.
\end{abstract}

\section{KEY WORDS: Immigrant women, found poetry, critical realism, homelessness}

\section{INTRODUCTION}

Feminist researchers have explored the daily-lived realities of women and the social inequalities that occur where gender intersects with societal values and political institutions (Ackerly, 2010; De Valt, 1996; Weber, 2007). Feminist research methods are rooted in a wide variety of epistemological and 
Hordyk, S-R, Ben Soltane, S and Hanley, J. (2013). Sometimes you have to go under water to come up: A poetic, critical realist approach to documenting the voices of homeless immigrant women. Qualitative Social Work 13(2): 203220 .

methodological approaches which emphasize the voice of women while identifying the power structures that have until now silenced them (Doucet, 2005; Fonow, \& Cook 2005). Weber (2007) has challenged feminist researchers to go even further, to not only identify the power relationships active in the lives of women but to examine the mechanisms of oppression that perpetuate this power. Though mechanisms that generate events are not always directly perceived, they are very real, producing 'discernable effects' (Houston, 2010, p. 75). Researchers must look specifically at how power relationships are coconstructed and which generative mechanisms influence their functioning. A critical realist analysis invites us to discern these processes that effect injustice as well as those which facilitate equitable outcomes. To most accurately represent the specific generating mechanisms influencing women's lives and to shape public policy, one must draw on not only on diverse methods of data analysis and but also diverse forms of representation (Lather, 2004; Weber, 2007).

Within feminist clinical social work practice, poetry has been used to empower clients (Kissman, 1989), primarily as a form of therapy (Cohen \& Johnson, 1997; Furman, Downey, Jackson, \& Bender, 2008; Mazza, 1996). Only recently are social workers beginning to implement poetry in research (Langer \& Furman, 2004). This research team had the task of analyzing immigrant women's stories of homelessness and housing insecurity and to represent these research findings to diverse audiences: research participants, social researchers, policy makers and the general public. We therefore accessed two writing techniques, comparing poetic analysis using a standard found poetry technique with a poetic analysis of the same interview based on the identification of generative mechanisms as identified in critical realist theory. We begin this article with a description of our project before offering an overview of the literature on both poetic inquiry and critical realism. We then elaborate on the process of writing and analysis found in each poetic re-construction of the women's narratives, 
Hordyk, S-R, Ben Soltane, S and Hanley, J. (2013). Sometimes you have to go under water to come up: A poetic, critical realist approach to documenting the voices of homeless immigrant women. Qualitative Social Work 13(2): 203220 .

concluding with some reflections on the place of poetic, critical realist representation of research findings.

\section{SHARING THE STORIES OF WOMEN}

This research began as a small government-commissioned study on immigrant women's experiences of homelessness and housing insecurity within their first 10 years of arrival in Canada. ${ }^{1}$ We conducted semi-structured interviews with 26 newcomer women and met with five key informants working in the shelter system. Interviews were conducted in English or French, though, for most women, these were their second or third languages. We asked women about their immigration trajectories including current immigration status, their post-arrival story of homelessness or insecure housing, their attempts to find housing solutions, and their sources of strength and support.

In our attempt to communicate the lived realities of newcomer women and housing to a variety of audiences, we analyzed and represented the data using three different techniques. One, we used the software NVIVO to identify and code significant themes present in the interviews. These were synthesized as major findings and discussed in our report to the government, to service providers, and to community groups (Walsh et al, 2011). Two, we used critical realist theory to identify the generating mechanisms spoken of by the immigrant women, mechanisms which fostered both inequitable and positive outcomes. These mechanisms were discussed at conferences and in community meetings. Three, we drew on poetic inquiry to analyze and represent the individual voices of several women. Poetic inquiry allowed us to analyze, re-construct and re-present the written transcripts, providing a

${ }^{1}$ The original study (Walsh et al, 2011) was funded by HRSDC Homelessness Partnering Secretariat. We would like to thank the other members of the team (Christine Walsh, Nicole Ives, Bora Mahano) and Sandy Sjollema for their part in the project behind this article. The voices of homeless immigrant women: a poetic, critical realist approach to research 
Hordyk, S-R, Ben Soltane, S and Hanley, J. (2013). Sometimes you have to go under water to come up: A poetic, critical realist approach to documenting the voices of homeless immigrant women. Qualitative Social Work 13(2): 203220.

three dimensional, embodied voice to women who had been made invisible, marginalized and silenced in their newfound country. Several of these poems were either portrayed or read in community events and were included in our government report.

\section{POETIC INQUIRY}

Poetry's strength lies in its capacity to awaken and transform the reader concerning subjects that may not have otherwise captured the imagination. Poetic forms of data representation are becoming increasingly commonplace in qualitative research with at least 40 terms used to describe how this has been accomplished (Prendergast, 2009). Lahman et al (2004) have described six major poetic research strategies: data poems in which the participants' own words are used to write poetry, participant poetry as data in which poems are collected from the research participant, autoethnographic poetry in which the researcher represents their personal experiences, research experience poems which represent the researchers' experiences in their study, cultural poetry research which looks at uses of poetry from an anthropological perspective, and poetic allusion in which researchers draw on the wider body of published poetry to use as references in their texts. We entered this research endeavor conscious of the enormous vulnerability faced by participants and of the many ways in which our social location already added a layer of subjectivity to our findings. We therefore turned to the data poem approach as this allowed us to highlight the voices of the women themselves. Within this approach we specifically borrowed on literature in found poetry (Bulter-Kisber \& Stewart, 2007) and poetic transcription (Glesne, 1997; Richardson 2002).

Poetic transcription and found poetry has been used by researchers to "privilege the importance of orality" in historically marginalized cultures. (Calafell, 2004, p. 180). This method invites the 
Hordyk, S-R, Ben Soltane, S and Hanley, J. (2013). Sometimes you have to go under water to come up: A poetic, critical realist approach to documenting the voices of homeless immigrant women. Qualitative Social Work 13(2): 203220 .

researcher to choose, eliminate, and move around participants' words to form an abstract representation of the essence of experience (Glesne, 1997; Faulkner, 2009). The chronology within prose is replaced by poetry in which there is constant interplay between parts and the whole. "The poem is a whole which makes sense of its parts and a poem is parts that anticipate, shadow, undergird the whole" (Richardson, 1993, p. 705). In the creation of a data poem, the researcher is representing the poetry as exact words of the interviewee, thus inviting some assumptions concerning reliability. Yet the interpretive process is poetic creation is no less present that in other forms of poetry. How might this paradox be understood?

\section{Expression in the face of oppression}

Oral and written language in all forms is at best an imperfect representation of human experience (Langer \& Furman, 2004). If all word symbols, written or spoken, fall short in portraying human occurrences, how do we make judgments between available mediums? If all research is intersubjective by nature, poetry highlights this space and offers words that can "open up the 'between' of intersubjective space" between research participant and the audience (Todres \& Galvin, 2008, p. 572). The reader is invited into relationship, to engage imaginatively with others and thus reduce the potential risk of objectifying categorizations of the other. Eisner (1991) describes the role of language in the arts to do justice to the unseen. Metaphor, lyric, emotion, imagery, rhythm and other language devices provide an alternative way of knowing (Prendergast, 2009). Poetic language penetrates experience, representing the sensory and evocative components of words not possible through linear representations (Furman, 2006). Poetry allows for a non-linear representation of data in which the multi-dimensional intersectionalities of women experiencing various forms of oppression due to race, gender, class or disability can be represented (Petersen, 2012). The integrity of the human "subject" is maintained as specifics can be noted among the generalities (Carroll, Dew \& Howden-Chapman, 2011) in this 
Hordyk, S-R, Ben Soltane, S and Hanley, J. (2013). Sometimes you have to go under water to come up: A poetic, critical realist approach to documenting the voices of homeless immigrant women. Qualitative Social Work 13(2): 203220.

interplay between the whole and its parts. Poetry, by virtue of its embodied expression, invites a personal response where the small ' $t$ ' truth of description becomes second to the large " $T$ " truth in which we see the other through "the eyes of the spirit" (Glesne, 1997 p. 213). In contrast to a more intellectualized form of listening, the body listens to poetry and in this listening, dualisms such as mindbody, intellect-emotion, self-other, researcher-researched on which science is based are collapsed (Richardson, 1993 p. 706).

\section{But is it art or is it research?}

The fraternization of poetry and research is not a hazard-free endeavor. Apprehensions concerning legitimacy and aesthetics arise among artists while discomforts concerning validity and reliability plague the researcher. These tensions, rather than suggesting that this undertaking should be abandoned, can be harnessed to refine poetic inquiry. Shapiro (2004) has suggested that qualitative researchers implementing poetic methods measure validity in the same way that all research is measured. Do the results make sense to the subject? Can other skilled observers agree with or accept the interpretations offered? Do methodology and conclusions stand up to informed criticism? Can results be triangulated with other forms of description? Do other researchers interacting with the data set arrive to the same conclusions? Has an audit trail been established? Has the researcher continued to revisit his/her interpretation? Depending on how these questions are answered in relationship to the data poem, conclusions concerning reliability and trustworthiness can be offered.

How does one define poetry and respect its art form in the context of research? Piirto (2009) has advocated that researchers who write poetry should at least have a background in poetry education. Bulter-Kisber (2010), however, gave a wider berth to researchers by differentiating between 'poet 
Hordyk, S-R, Ben Soltane, S and Hanley, J. (2013). Sometimes you have to go under water to come up: A poetic, critical realist approach to documenting the voices of homeless immigrant women. Qualitative Social Work 13(2): 203220 .

researchers' and 'researcher poets.' She has argued that researchers who are not poets first are capable of poetic representation if willing to develop craft and technique. Clearly, poorly written poetry does disservice both to poet artists and research participants. Yet how does one measure 'good poetry' when the audience consists of research participants, community members, and experts in one's field of study? Based Baron and Eisner's criteria for measuring art in research (2006), we argue that poetic success in social work research is established when the reader/listener has been illuminated, his or her curiosity aroused, the "heart of the matter" clearly identified, and when relevance to a population beyond the participant is made evident. These criteria invite poetry to be simultaneously judged by art critic, research participant and the public alike.

\section{CRITICAL REALISM}

Critical realism posits that we live in three overlapping domains of reality: a) the real, referring to causative and generative mechanisms; b) the actual, a term used to describe an event itself and c) the empirical, referring to the actual perception of the experience of the event by the individual (Bhaskar, 1975). Mechanisms exist separately from the events that they generate. Events are distinct from the experiences in which they are grasped (Bhaskar, 1975). Critical realism is valuable to the social sciences in its emphasis on the root causes and social structures underlying oppression (Houston, 2001). A critical realist perspective in qualitative migration research is advantageous as it can reveal the interplay between real causative powers (ex. gender, ethnicity and class) and real complex social relations; it allows for an identification of the generative, causative mechanisms of migration related phenomena (Iosifides, 2011). For many of the same reasons that we were drawn to poetry, as social workers, we were compelled by the potential in this form of data analysis and representation. 
Hordyk, S-R, Ben Soltane, S and Hanley, J. (2013). Sometimes you have to go under water to come up: A poetic, critical realist approach to documenting the voices of homeless immigrant women. Qualitative Social Work 13(2): 203220 .

The women's narratives indicated that homelessness in a wealthy country was an unexpected and difficult to explain outcome of their immigration process. Women could speak articulately of their subjective experiences, but often had incomplete or inaccurate explanations of how their experiences were related to external systems, structures or policies. Few women were aware of how local housing markets and government housing policies had influenced their trajectories into homelessness. They were more clear in identifying structural powers and barriers related to immigration policies, language requirements and discrimination by landlords, janitors or others. This is consistent with the findings of Clark, Lissel and Davis (2008) who have stated that perceptions of the empirical domain are at best "fallible representations of the real and actual domains... prone to incompleteness and inaccuracies of perception" (p. 69).

Based on our interviews, we deconstructed the unseen/generative mechanisms identified by the women as shaping their current housing situation (the real), the local realities concerning these generative mechanisms, in this case, Montreal, Canada (the actual), and women's personal experiences, both positive and negative, concerning these mechanisms (the empirical). What remained was a 'theory of emergence' (Elder-Vas, 2004, p. 12), a complex analysis of the multiple levels of generative mechanisms leading to homelessness in the actual local housing and employment context (see Table 1).

\begin{tabular}{|l|l|l|}
\hline \multicolumn{1}{|c|}{$\begin{array}{c}\text { Domain of } \\
\text { Real }\end{array}$} & \multicolumn{1}{|c|}{ Domain of Actual } & \multicolumn{1}{c|}{$\begin{array}{c}\text { Domain of Empirical } \\
\text { Negative and } \\
\text { Positive experiences }\end{array}$} \\
\hline Race/ethnicity & $\begin{array}{l}\text { Majority of recent immigrants are } \\
\text { people of colour, in contrast with the } \\
\text { 'white' majority of Canadians }\end{array}$ & $\begin{array}{l}\text { Discrimination, betrayal } \\
\text { Community links, cultural strengths }\end{array}$ \\
\hline Gender & $\begin{array}{l}\text { Women overrepresented in nearly } \\
\text { all precarious categories of } \\
\text { immigration }\end{array}$ & $\begin{array}{l}\text { Job and housing discrimination, safety } \\
\text { concerns, social isolation } \\
\text { Community }\end{array}$ \\
\hline $\begin{array}{l}\text { Class/ income } \\
\text { level }\end{array}$ & $\begin{array}{l}\text { Immigrant women- lowest incomes } \\
\text { of all groups, lack of credit history } \\
\text { or money for down payments }\end{array}$ & $\begin{array}{l}\text { Exploitation in low paying jobs } \\
\text { Difficulty to find adequate housing } \\
\text { Awareness of justice and rights }\end{array}$ \\
\hline
\end{tabular}

The voices of homeless immigrant women: a poetic, critical realist approach to research 
Hordyk, S-R, Ben Soltane, S and Hanley, J. (2013). Sometimes you have to go under water to come up: A poetic, critical realist approach to documenting the voices of homeless immigrant women. Qualitative Social Work 13(2): 203220.

\begin{tabular}{|c|c|c|}
\hline Housing market & $\begin{array}{l}\text { Condo construction valued over } \\
\text { public housing construction. } \\
\text { Housing costs up } 30 \% \text { between } \\
2000 \text { and } 2009 . \\
\text { Services on local and federal levels } \\
\text { to meet housing needs }\end{array}$ & $\begin{array}{l}\text { Difficulty finding safe, suitable, } \\
\text { adequate and affordable housing, } \\
\text { landlord abuse } \\
\text { Qualify for social services }\end{array}$ \\
\hline Language & $\begin{array}{l}\text { French and English employment } \\
\text { requirements }\end{array}$ & $\begin{array}{l}\text { Problems in access to employment and } \\
\text { housing due to accent discrimination } \\
\text { or lack of language proficiency } \\
\text { Connections due to shared native } \\
\text { language }\end{array}$ \\
\hline $\begin{array}{l}\text { Culture: norms } \\
\text { around food, } \\
\text { communication, } \\
\text { decision-making } \\
\text { process etc. }\end{array}$ & $\begin{array}{l}\text { Dominant culture shapes how } \\
\text { services are offered: health care, } \\
\text { shelters, education, job protocol, } \\
\text { obtaining housing }\end{array}$ & $\begin{array}{l}\text { Steep cultural learning curves } \\
\text { including housing, transportation, } \\
\text { currency, food. } \\
\text { Drawing on culture-based strengths }\end{array}$ \\
\hline $\begin{array}{l}\text { Family and } \\
\text { community }\end{array}$ & $\begin{array}{l}\text { Increased diversity in immigrant } \\
\text { family constellations and histories. } \\
\text { Breakdown of family units in } \\
\text { immigration process }\end{array}$ & $\begin{array}{l}\text { Trauma, abuse, harassment, } \\
\text { exploitation, discrimination. Barriers } \\
\text { due to presence of children. Need to } \\
\text { send money to home country. } \\
\text { Family/ community as support, } \\
\text { resource, motivation to continue }\end{array}$ \\
\hline $\begin{array}{l}\text { Formal education } \\
\text { level }\end{array}$ & $\begin{array}{l}\text { Immigrants entering work force } \\
\text { often with higher levels of education } \\
\text { and work experience than native- } \\
\text { born populations }\end{array}$ & $\begin{array}{l}\text { Employers hesitant to hire immigrant } \\
\text { workers even with paid government } \\
\text { incentives. } \\
\text { Education level as pathway for } \\
\text { integration }\end{array}$ \\
\hline Immigration status & $\begin{array}{l}\text { A wide range of statuses confer } \\
\text { different rights on different people }\end{array}$ & $\begin{array}{l}\text { Lengthy separations from family; } \\
\text { housing service and employment } \\
\text { barriers } \\
\text { Access to services increasing with } \\
\text { permanency status }\end{array}$ \\
\hline
\end{tabular}

Table 1 DOMAINS OF REAL, ACTUAL AND EMPIRICAL IN IMMIGRANT WOMEN'S HOUSING SITUATION

\section{INTEGRATING FOUND POETRY AND CRITICAL REALIST THEORY}

Our process of research representation took place as follows: 1) transcribing of interviews; 2) team discussion of major themes; 3) NVIVO coding based on these themes and additional subthemes; 4) poetry created from poetic transcription based on general readings of the transcripts; 5) chart created from a critical realist analysis of the data; 6) re-coding of interviews based on categories of the real 
Hordyk, S-R, Ben Soltane, S and Hanley, J. (2013). Sometimes you have to go under water to come up: A poetic, critical realist approach to documenting the voices of homeless immigrant women. Qualitative Social Work 13(2): 203220.

emerging from the critical realist analysis; and 7) poetry created from poetic transcriptions limited to excerpts related to one specific domain.

While representing findings at a local women's center, we used a traditional PowerPoint medium and complemented this with an art exhibit of found poems based on our interviews. When meeting with local women's shelters and academic audiences we represented results primarily through the abovementioned critical realist findings chart. At one point we asked ourselves, how might found poetry arising from a critical realist analysis be different?

Sullivan's (2009) criteria in finding an appropriate interview for poetic inquiry provided guidance to choosing our first research participant to represent through poetry. Was the woman concrete in her expression and did her material have an associative logic? Was the uniqueness of her voice accessible in the text? Could we find the emotion, tension and ambiguity in her text? For the purposes of this paper, we chose two participants' interviews to illustrate the differences in a poetic transcription as described in the literature and a poetic transcription rooted in critical realism. The first poem was written using a found poetry technique in which the researcher combed through the text choosing both repeating and significant phrases to create a poem. Significant phrases were those which appeared central to the women's story or which were especially poignant in illustrating a particular theme. For the second poem, the researcher coded the same interview according to the generative mechanisms that had been identified in the larger body of women's stories and created a poem based on the most frequently represented mechanisms. We will present our poems here with a short synopsis of what was discovered.

\section{POETRY AND ANALYSIS}


Hordyk, S-R, Ben Soltane, S and Hanley, J. (2013). Sometimes you have to go under water to come up: A poetic, critical realist approach to documenting the voices of homeless immigrant women. Qualitative Social Work 13(2): 203220.

\section{PARTICIPANT \# 1, FOUND POETRY}

Our first discussion is based on an interview with a woman who had responded to a research recruitment poster hung in a housing advocacy organization. She had arrived as an undocumented worker, applied for refugee status, and at the time of the interview, had gained citizenship. Her two children joined her only after she had gained permanent residency. Since arriving four years ago, she had lived in two large Canadian cities in at least 6 different housing arrangements.

\section{What if that was me?}

\section{I told my landlord}

There's rusty water comin' from the pipe

"Oh the pipes are good."

I can't drink the water.

"Oh, the pipes are good."

I haven't used the water, even to cook!

He keep sayin', "oh the pipes are good."

I told the secretary, I'm having problems with the apartment.

"No."

Bumps keep comin' on my skin. Come, I have to show you somethin' because they bugs!

"Maybe you're the one that brought the bugs here."

I took my friend to the office. He start swearin'.

"Oh I'm sorry... well maybe the apartment was already infested because an old guy was livin' there," she says.

But no, she didn't want to give back my refund. 
Hordyk, S-R, Ben Soltane, S and Hanley, J. (2013). Sometimes you have to go under water to come up: A poetic, critical realist approach to documenting the voices of homeless immigrant women. Qualitative Social Work 13(2): 203220.

They don't treat fair, especially when you're an immigrant.

They're tellin' you:

"You're tryin' to take our space."

“And we're not rentin' to you."

"Maybe you'll trash our apartment."

You do find people like that.

But you have to think, what if that was me?

This first poem was written as the author re-read the text as a whole, looking for repetition, emphasis, emotion, and key phrases concerning housing conditions. It quickly became clear that throughout the interview, the participant shifted between her own voice and that of her oppressors. To explore this further, several pages of transcript excerpts were arranged into two columns. The first column contained the participant's representation of her own voice; the second portrayed the words that she ascribed to those she viewed as wielding power. This included the landlord, the janitor, the board members of the housing co-operative and her fellow citizens. Her interview contained several recreations of this back and forth dialogue interspersed with descriptions of her historical context and personal interpretations. Two portions of her transcript capture her words in linear form:

...then he keep sayin' oh the pipes are good, and there was rusty water coming from the pipe, and I keep tellin' him that I'm not gonna drink the water and in months I haven't even used the water to even cook and at the shower the water used to be itchin' my skin and stuff and I went and I told him and he telled me you know what? You gettin' this is one, ah, you can't get no apartment no cheaper than this and knowin' that you not even qualified with the right documents... 
Hordyk, S-R, Ben Soltane, S and Hanley, J. (2013). Sometimes you have to go under water to come up: A poetic, critical realist approach to documenting the voices of homeless immigrant women. Qualitative Social Work 13(2): 203220 .

...it was in falls and it was getting' cold and he kept tellin' me oh the heat is supposed to be turned on a certain time in fall and I'm like, but it's cold in the apartment. You know it was really cold. And he said, ok, so you have to buy your own uh heatin' system and I had no idea what is going on because it's my first time having a, owning my own apartment....

The poetic form allowed us to portray strong themes of injustice and discrimination located throughout her dialogue, themes that she attributed in her interview to her lack of citizenship status and to her racialized identity. The author chose to portray these themes in the poetry as they had been present in the stories of many of the women whom we interviewed. What was unique to this participant was her sense of personal agency. This theme, though present in all of our interviews, was most visible in this narrative. She persistently used her voice to demand justice. Again, following the guidance of Barone and Eisner (2006), the intent of the poem is to illuminate awareness concerning discrimination, stimulate curiosity concerning how this is experienced, communicate the heart of this women's desire to find both a physical and emotional home, and to provide information that others reading this poem may relate to.

\section{PARTICIPANT \#1, A CRITICAL REALIST APPROACH TO FOUND POETRY}

Poetic inquiry is the interpretation of a verbal landscape. Like the photographer confronted by a visual landscape, the researcher poet chooses from a variety of lenses through which to re-construct this verbal landscape. This next poem will illustrate the use of a critical realist lens to interpret this same woman's story. In the writing of this poem, the transcript of the interview had been re-coded using the categories listed in the 'domain of the real' in our chart, a list shaped by all 26 interviews. The researcher then recoded the woman's interview to determine which domains in this particular interview were referred to most frequently and out of these domains, which were most amenable to poetry. In paying attention to 
Hordyk, S-R, Ben Soltane, S and Hanley, J. (2013). Sometimes you have to go under water to come up: A poetic, critical realist approach to documenting the voices of homeless immigrant women. Qualitative Social Work 13(2): 203220.

language, tone and frequency of reference, a paradox emerged. The intersections of cultural identification and race played heavily in this woman's story both as barrier and source of hope.

$\underline{W e}$

We're the immigrants.

We speak in English.

We have a dialect.

We develop your country more than you would ever know.

We try to come and look alike

We try to come and make a livin'.

We come here knowin' that

We have to get a job.

We work.

We are independent.

We are owning our own apartment.

We have our own money.

We take care of our kids and our babies.

We take care of our family in our home country.

We are strong.

We're the immigrants.

I recommend to other women:

Try to stay with it. 
Hordyk, S-R, Ben Soltane, S and Hanley, J. (2013). Sometimes you have to go under water to come up: A poetic, critical realist approach to documenting the voices of homeless immigrant women. Qualitative Social Work 13(2): 203220.

Sometimes you have to go under water to come up.

Don't let go.

There's always a solution.

Go and help yourself.

You're here livin' and you have to see yourself livin' as a Canadian.

Though the first attempt at poetry had highlighted the research participant's individual strength and vulnerability in the face of oppression, poetry based on a critical realist analysis made it clear that strong culture, migrant, and gender identifications were at work. What had gone completely unnoticed until coding for generative mechanisms, as both positive and negative influences in her trajectory, was the interviewee's use of the word 'we'. She had a strong cultural identification with women in her home country as well as with this newfound culture of immigrant women. Though it was not always clear in her discourse as to which was being referred to.

In the linear process of transcript representation, we may draw on a text such as the one listed below.

We are, we are, we are strong in our own mind, you know so, cause if we could take a kid for 9 months, why can't we take a usage of our life for nine months or more or extended so be strong all the time 'cause you have to be strong for yourself and also for your kids so I'll tell them to just be strong, that's it.

A nonlinear form of representation, however, allows us to draw on a theme weaving throughout her interview:

We are independent... We would try to work....We try to enjoy every moment that we have back home...We are strong....We could take a baby for nine months, why can't we make use 
Hordyk, S-R, Ben Soltane, S and Hanley, J. (2013). Sometimes you have to go under water to come up: A poetic, critical realist approach to documenting the voices of homeless immigrant women. Qualitative Social Work 13(2): 203220 .

of our life for nine months more? We the humans make the world chaotic... We should live in harmony...We need to enlighten our love.

Though the interviewee had discussed how various categories of the domain of the real had influenced her housing situation, for both good and bad, poetic inquiry based on a critical realist analysis revealed that her sense of independence was in fact rooted in a sense of belonging to multiple cultural groups. And surprisingly, in the face of adversity, she widens her use of "we" to include the oppressors within her host country.

\section{PARTICIPANT \# 2, FOUND POETRY}

The second research participant to be discussed had been recruited by a local women's shelter. She had experienced significant trauma in her personal life before immigrating, growing up in a war torn country. The sheer number of cultural and housing settings this woman had negotiated to come this far was astonishing: from home country to refugee camp to an African university to a European university residence to a Canadian university residence to an adult foster home to two different monastic boarding arrangements to shelter \#1 to shelter \# 2 to shelter \#3 and to shelter \#4 - which is where we caught up with her. She was about to lose her place in the last shelter because she had chosen to stop taking her medications. Highly educated, she had enrolled in a Canadian university to continue her studies, only to experience a psychological breakdown that she described as being due to "a difficult welcome that had been reserved for me" though did not elaborate. The associative logic in her material was not immediately evident. The effects of her trauma were seen in her interview as she rarely answered questions directly and spoke in a disjointed, non-linear and random fashion. At times her words were 
Hordyk, S-R, Ben Soltane, S and Hanley, J. (2013). Sometimes you have to go under water to come up: A poetic, critical realist approach to documenting the voices of homeless immigrant women. Qualitative Social Work 13(2): 203220.

indecipherable. She shared that she was hospitalized from time to time and was under the care of a psychiatrist.

\section{$\underline{\text { I am an immigrant }}$}

I am an immigrant, that is to say, a landed immigrant.

When I received the papers that said I was a landed immigrant

I took my suitcases and I left.

Only me...my brother did not join me.

I am afraid.

I am afraid of things like fire.

I am afraid.

I don't have enough money on me.

I moved around,

an immigrant going from house to house.

I had to survive winter, and I did.

I am an immigrant.

I remain calm.

The worry is in my head.

I want to sleep, I want to forget a little,

I forget a little.

The image of my mother...

"Sleep, I love you!

Because I love you, I want to see you with the others. 
Hordyk, S-R, Ben Soltane, S and Hanley, J. (2013). Sometimes you have to go under water to come up: A poetic, critical realist approach to documenting the voices of homeless immigrant women. Qualitative Social Work 13(2): 203220.

Everyone else is there, talking, while you are silent."

What is in my mind,

Immersed in Africa...

Tell me your story.

I would like to heal.

The healing of wounds...

They come like a dream,

like the dreams of a child,

the desire of a child to be somewhere and to belong.

The interview on which this poem was based was conducted in French by a researcher whose first language was English. As a result, a Francophone team member wrote the found poem. As she had neither administered nor transcribed this interview, the poetry writing process took on a different meaning. Her initial impressions of the transcription were that of loneliness and inadequacy on the part of the participant; her words appeared flat and difficult to access. Themes of homelessness were not clearly seen in the transcript and the meanings in the text were difficult to determine. Curiously, the process of writing this poem changed her perceptions. As she combed through the transcript selecting words that were repetitive or that struck her as having particular potency, it became clear to that there was more to this interview than had initially been evident.

\section{PARTICIPANT \#2, A CRITICAL REALIST APPROACH TO FOUND POETRY}

This interview was also recoded using the domains of the real coming from a critical realist analysis. What emerged in the coding was the fact that interviewee and interviewer were each preoccupied with 
Hordyk, S-R, Ben Soltane, S and Hanley, J. (2013). Sometimes you have to go under water to come up: A poetic, critical realist approach to documenting the voices of homeless immigrant women. Qualitative Social Work 13(2): 203220.

two different though very related concerns. Our participant had agreed to an interview about housing and our NVIVO coding allowed us to look at her responses and categorize them. But when we took the generating mechanisms she found most prevalent and placed them in poetic form, it became clear that she was very concerned about her ongoing food insecurity. Some of the confusion we had attributed to mental suffering may have been due, in fact, to the interviewer's efforts to remain with an identified research question and interview outline when the participant's preoccupations were elsewhere. We therefore changed tracks to write this poem and compiled phrases in which she referenced food. We broke these down into themes of food storage, food history, food preferences, food customs and traditions, food availability, food survival strategies and miscellaneous statements around food. Within these categories, a narrative emerged comparing the story of what she referred to as the North American, the African and the Immigrant/Refugee. Phrases were organized in titles and text to represent this narrative, then translated into English before the poem was written. In the first verse, the word grocery store replaces the local chain store name she had used, the Metro.

\section{Food security: the number of meals one has to seek for oneself}

In the North American context

one drinks lots of coffee;

one uses refrigerators;

one goes to the grocery store;

it's totally different, there really isn't a lack of food... maybe lack of food that one is accustomed to.

In an African family 
Hordyk, S-R, Ben Soltane, S and Hanley, J. (2013). Sometimes you have to go under water to come up: A poetic, critical realist approach to documenting the voices of homeless immigrant women. Qualitative Social Work 13(2): 203220.

the strategy to survive is food security;

this is what has affected me most in my life.

The refugee receives 250 grams of flour,

250 grams of oil-

food rations for two weeks.

I try to have a strategy to survive- to know right away

what will be there

and what won't be there.

Musi-art-coffee, ticket for the cafeteria.

Women's centers- hot drinks

Concert at the Atwater library- soup, pie, a box of chocolate cookies.

The following excerpt provides the context for her survival choices. She began with "I" and then shifted to the French term for "one." Whether she is seeking to describe her survival strategy in a less personalized sense and/or if she is stating that she sees herself representing one of many, we don't know. Referring to her music therapy, musi-art, she states:

I really improved in terms of the number of performances and in terms of performances also the number of songs one could sing. One really improved in terms of food insecurity and food insecurity is the amount of food one must seek for oneself ... where one lets oneself be led by the other, one has to sacrifice here and there, but all the same one moves to assure that one is secure food-wise... 
Hordyk, S-R, Ben Soltane, S and Hanley, J. (2013). Sometimes you have to go under water to come up: A poetic, critical realist approach to documenting the voices of homeless immigrant women. Qualitative Social Work 13(2): 203220 .

"Sacrifice", "being led;" how might these terms provide clues as to which generative mechanisms are at work in the service of which systems of domination? We may not have enough information to draw conclusions. We do know however, that this participant is very aware of those in power and makes active choices in relationship to those for the sake of her survival.

\section{DISCUSSION}

Feminist researchers seek to improve the status of women by engaging in a dialogue with them about their lives and concerns with the eventual goal of social change (DeVault, 1996). We have found that the use of found poetry in combination with a critical realist analysis of research data to be consistent with feminist research methodologies. By implementing this method of data analysis and representation, we have been able to identify more clearly where our subjectivity lay when it would otherwise have remained hidden. Through poetry writing, we reconsidered previously held assumptions and became aware of additional themes in the interviews. In the first above-mentioned example, a newcomer initially appeared to be isolated as a self-advocate in repeated situations of exploitation by landlords. Through this process of analysis, we saw that she was constantly acting in the context of in internalized and external community. In the second example, a participant's fragmented pattern of thought had not allowed us to identify her salient themes using typical data coding software. We could engage in a reflexive analysis concerning our own reactions and responses to this interview as we approached the interview through the lens of poetic analysis. The coherence that was present in her story could then be seen, understood and represented, making her story more accessible.

The critical realist lens allowed us to identify which generating mechanisms were most salient to individual participants, determining which 'domains of the real' functioned primarily as barriers to 
Hordyk, S-R, Ben Soltane, S and Hanley, J. (2013). Sometimes you have to go under water to come up: A poetic, critical realist approach to documenting the voices of homeless immigrant women. Qualitative Social Work 13(2): 203220.

housing and which domains were a significant source of strength for the women. Returning to the transcriptions and writing poetry based on categories emerging from domains of the real also allowed us to identify which mechanisms each woman was herself most aware of and to what degree. We noted, for example, that few women were aware of local housing trends, immigration patterns and economic changes. Unaware of how these changing realities may have generated some of their difficulties, their efforts to succeed were potentially hindered even more. However, rather than only remaining focused on the barriers to housing and external support structures, we could identify the positive generating mechanisms in each woman's story, thereby portraying the women in our study not only as victims of history and politics but also as active agents in their own lives. This information served to valorize women themselves, to support certain initiatives already taken by community organizations, and to providing new ideas to direct service providers.

The process of writing poetry based on traditional found poetry methods and that based on critical realist data analysis will have a significantly distinctive transforming influence on the researcher. This distinction may not be evident in the poem itself and therefore may not have that same effect on the reader. This difference allowed us to see how generative mechanisms might be experienced by the individual due to how the language changed when these themes were touched upon. Some domains had more of a flat presentation and others much more dynamic, indicating less despair than a linear analysis would indicate. In addition, the women we spoke to communicated in French or English, a second or third language for most. The attentiveness to language inherent in poetic methodology invited us to discover some of what became lost in translation between differences in language, culture, history and social location. We were invited to step out of our methodological frame- transcribing, creating themes, 
Hordyk, S-R, Ben Soltane, S and Hanley, J. (2013). Sometimes you have to go under water to come up: A poetic, critical realist approach to documenting the voices of homeless immigrant women. Qualitative Social Work 13(2): 203220 .

coding, consolidating, writing, and revisit the words of the women outside of this framework. This allowed alternative meanings to emerge.

Finally, the use of poetry as data representation invites a wider audience into the dialogue than an academic report does while actively engaging the audience. The audience is required to respond in one way or another as the art form does not allow them to remain passive recipients. Based on community feedback, we found that poetry elicited emotional responses concerning specific aspects of the women's stories. It allowed us to make visible what our participant's passions and allowed us to respect individual identities; this in contrast to voices being obscured by summaries of what we determine to be most salient based on the voice of the majority.

\section{CONCLUSION:}

Transcriptions, coded interview texts and reports risked reducing our research participants to a twodimensional text, women vulnerable, helpless and homeless. A critical realist analysis allowed us to see where the strengths of these newcomers lie without minimizing the reality of their plight. The word inquiry in poetic inquiry is under-emphasized in the literature. In looking at our interviews with an inquisitive mind, we were able to discover and re-present the embodied voice of the research participants- concerned, angry, hopeful, afraid, grieving, intelligent, aware, courageous. Found poetry, in the context of a critical realist approach to data analysis, can serve to invite a wider audience into the dialogue with oppressed and vulnerable populations while deepening the researcher's understanding of generative mechanisms shaping social issues.

\section{References}

Ackerly B, True J (2010) Back to the future: Feminist theory, activism, and doing feminist research in an age of globalization. Women's Studies International Forum (33)5: 464-472 
Hordyk, S-R, Ben Soltane, S and Hanley, J. (2013). Sometimes you have to go under water to come up: A poetic, critical realist approach to documenting the voices of homeless immigrant women. Qualitative Social Work 13(2): 203220.

Barone T, Eisner E (2006) Arts-based educational research. In: Green, Camilli, Elmore (eds) Handbook of Complementary Methods in Education Research. Mahwah, N.J: Lawrence Erlbaum Associates. pp. 95-109

Bhaskar R (1975) A realist theory of science. York: Books

Butler-Kisber L (2010) Qualitative inquiry: Thematic, narrative and arts-informed perspectives. Los Angeles: SAGE

Calafell, B. M. (2004). Disrupting the Dichotomy: Yo Soy Chicana /o in the New Latina /o South. The Communication Review, 7(2), 175-204.

Carroll P, Dew K, \& Howden-Chapman P (2011) The Heart of the Matter: Using Poetry as a Method of Ethnographic Inquiry to Represent and Present Experiences of the Informally Housed in Aotearoa/New Zealand. Qualitative inquiry, 17(7), 623-630.

Clark A, Lissel S, Davis C (2008) Complex critical realism: Tenets and application in nursing research. Advances in Nursing Science 31(4): E67-E79

Cohen M, Johnson J (1997) A self-directed community group for homeless people: Poetry in motion. In: Parry J (ed) From Prevention to Wellness through Group Work. New York: Haworth Press. pp. 131-142

DeVault, M L (1996) Talking back to sociology: Distinctive contributions of feminist methodology. Annual review of sociology 22: 29-50.

Doucet A, Mauthner N S (2006) Feminist methodologies and epistemologies. In Bryant D, Peck D (eds) Handbook of 21 st Century Sociology. Thousand Oaks, CA : Sage. pp. 36-42

Eisner, E. W. (1991). The enlightened eye: Qualitative inquiry and the enhancement of educational practice. New York, N.Y: Toronto.

Elder-Vas D (2004) Re-examining Bhaskar's three ontological domains: The lessons from emergence. http://131.111.165.101/csog/iacr/papers/Elder-Vas.pdf (Accessed August 2012)

Fonow M, Cook J (2005) Feminist methodology: New applications in the academy and public policy. Signs 30(4): 2211-2236

Furman, R (2006). Poetic Forms and Structures in Qualitative Health Research. Qualitative Health Research, $16(4), 560-566$.

Furman R, Downey E, Jackson R, Bender K (2008) Poetry therapy as a tool for strengths-based practice. Advances in Social Work 3(2): 146-157.

Houston S (2001) Beyond social constructionism: critical realism and social work. British Journal of Social Work 31(6): 845-861.

Houston S (2010) Prising open the black box. Qualitative Social Work 9(1): 73-91.

The voices of homeless immigrant women: a poetic, critical realist approach to research 
Hordyk, S-R, Ben Soltane, S and Hanley, J. (2013). Sometimes you have to go under water to come up: A poetic, critical realist approach to documenting the voices of homeless immigrant women. Qualitative Social Work 13(2): 203220.

Iosifides T (2011) Qualitative methods in migration studies: a critical realist perspective. Burlington, VT: Ashgate.

Kissman K (1989) Poetry and Feminist Social Work. Journal of Poetry Therapy 2(4): 221-30.

Lahman, M, Geist M, Rodriguez K, Graglia P, Richard V \& Schendel, R (2010). Poking Around Poetically: Research, Poetry, and Trustworthiness. Qualitative inquiry, 16(1), 39-48.

Langer C, Furman R (2004) Exploring identity and assimilation: Research and interpretive poems. Paper presented at the Forum Qualitative Sozialforschung/Forum: Qualitative Social Research.

Lather P (2004) Critical inquiry in qualitative research: Feminist and poststructural perspectives: Science after truth. In: de Marrais K, Lapan S D (eds) Foundations for Research: Methods of Inquiry in Education and the

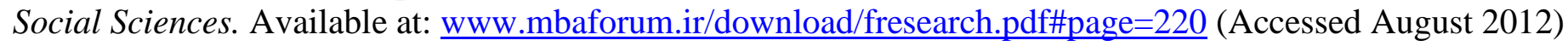

Mazza N (1996) Poetry therapy: A framework and synthesis of techniques for family social work. Journal of Family Social Work 1(3): 3-18.

Petersen A (2012) Imagining the possibilities: qualitative inquiry at the intersections of race, gender, disability, and class. International Journal of Qualitative Studies in Education 25 (6) 801-818

Piirto J (2009) The question of quality and qualifications: writing inferior poems as qualitative research In Prendergast M, Leggo, Sameshima P (eds) Poetic inquiry: Vibrant voices in the social sciences. Boston: Sense Publishers. pp. 83-100

Prendergast M (2009) Introduction: The phenomena of poetry in research: 'Poem is what?' Poetic inquiry in social science research. In Prendergast M, Leggo, Sameshima P (eds) Poetic inquiry: Vibrant voices in the social sciences. Boston: Sense Publishers. pp. xix-xlii

Richardson L (1993) Poetics, Dramatics, and Transgressive Validity: The Case of the Skipped Line. The Sociological Quarterly, 34(4), 695-710.

Richardson L (2002). Poetic representations of interviews. In J F Gubrium and J A Holstein (Eds). Handbook of interview research: context and method. Thousand Oaks, CA, Sage.

Shapiro J (2004) Can Poetry Be Data? Potential Relationships Between Poetry and Research. Families, Systems, \& Health, 22(2), 171-177.

Sullivan A M (2009) On poetic occasion in inquiry: concreteness, voice, ambiguity, tension, and associative logic. In Prendergast M, Leggo, Sameshima P (eds) Poetic inquiry: Vibrant voices in the social sciences. Boston: Sense Publishers. pp. 111-126

Todres L, Galvin K (2008) Embodied interpretation: a novel way of evocatively re-presenting meanings in phenomenological research. Qualitative Research 8(5), 568-583.

Walsh, A., Hanley, J., Ives, N. Hordyk, S.R., Mohano, B. (November 2011) Uncovering Invisibilities: Understanding 
Hordyk, S-R, Ben Soltane, S and Hanley, J. (2013). Sometimes you have to go under water to come up: A poetic, critical realist approach to documenting the voices of homeless immigrant women. Qualitative Social Work 13(2): 203220.

Experiences of Newcomer Women across the Homeless Spectrum. A report prepared for the Homelessness Partnership Strategy, HRSDC.

Weber L (2007). Future directions of feminist research: new directions in social policy: the case of women's health. In: Hesse-Biber, SN (ed) Handbook of feminist research: Theory and praxis. Thousand Oaks, Calif: SAGE Publications. pp. 669-678 